\title{
LAS MUJERES EN PAKISTÁN O EL PODER DEL PATRIARCADO
}

Ma José Clavo Sebastián Universidad de La Rioja

RESUMEN: En este trabajo resaltamos algunos de los aspectos culturales pakistaníes que más afectan a las mujeres y que nos permiten conocer, en parte, el modo en que este colectivo se encuentra inmerso en una situación de fuerte discriminación respecto al varón. Tratamos de explicar los mecanismos de perpetuación de esta situación utilizados en esa sociedad. Consideramos el más decisivo la división sexual del trabajo y la imposición desde el poder de medidas sociales androcéntricas sobre la educación, el mercado laboral y la participación política que sitúan a las mujeres en una posición de inferioridad y dependencia respecto del varón. Esta posición de desventaja social se refuerza mediante la defensa y legitimación desde el poder, masivamente masculino, de la ideología de sexo y las normas sexuales tradicionales, que obstruyen las posibilidades de desarrollo personal femenino. De este modo se mantiene y reproduce el orden patriarcal en el que las mujeres deben encontrarse subordinadas a los varones.

Palabras clave: Mecanismos del patriarcado, medidas sociales androcéntricas, ideología de género, normas sexuales.

\section{WOMEN IN PAKISTAN OR THE POWER OF PATRIARCHY}

ABSTRACT: This paper highlights some cultural aspects of Pakistan which affect women, as a better knowledge of these aspects helps to improve our understanding of the strong discriminatory practices that these women suffer. We seek to explain the mechanisms used by Pakistani society to perpetuate the subjection of women. Sexual division of labour and the imposition of sexist patterns in education, labour market and participation in politics are the main restrictions applied to women, which are thus kept in a subordinate position. This social disadvantage is reinforced from the power, mainly exerted by men, and its defence and legitimization of traditional sexual roles, which burden 
the emancipation of women. Patriarchal rules are thus reproduced in order to guarantee the subordination of Pakistani women.

Keywords: Mechanisms of Patriarchy, androcentric social rules, gender ideology, sexual rules.

Pakistán es un país complejo y se encuentra habitado desde generaciones por diferentes tribus que poseen su propia tradición, su propia lengua, sus propios sistemas de justicia, y sus propias fidelidades y adhesiones. Este país fue invadido por los musulmanes en el s.VIII, y como consecuencia se llevó a cabo un proceso de islamización que generalizó la fe y la práctica de esta religión en todo el país. Durante la época de la colonización británica, Pakistán, que entonces formaba parte de India, recibió la influencia de la cultura del Reino Unido y algunos aspectos importantes de ella han sido integrados y continúan vigentes. Estos tres elementos: los sistemas tribales, la religión islámica y cultura británica, con sus fricciones, conviven y coexisten conformando un país peculiar. Sólo teniendo en cuenta esta peculiaridad podemos entender la formación de la identidad de género que, entre otras cosas, depende de estos factores.

A pesar de esta gran diversidad y confrontación existen una serie de elementos culturales que son compartidos por todas las etnias, tribus y secciones religiosas, y que afectan directamente a la situación de las mujeres. Estos elementos son: la estructura patriarcal dominante, el significado del honor de la familia y sus consecuencias sobre las relaciones de género.

Las actitudes patriarcales se encuentran omnipresentes en el país, y con ellas los estereotipos culturales y tradicionales, profundamente arraigados, que establecen los papeles y las responsabilidades de las mujeres y los hombres en la familia, en el trabajo y en la sociedad, ello constituye un serio obstáculo para el establecimiento de la igualdad entre mujeres y hombres en todos los ámbitos sociales, públicos y privados.

La estructura social patriarcal se encontraba implantada en el país con anterioridad a la invasión musulmana. Posteriormente esta religión asumió y legitimó la situación de privilegio de los varones sin dificultad, y la conjunción de ideas y valores de las tradiciones tribales y el Islam ha construido la tradición patriarcal de ese pueblo y es uno de los aspectos más importantes de su cultura.

Elisa Giunchi, una importante investigadora de la cultura pakistaní indica, en su trabajo sobre la situación de la mujer en Pakistán que:

"La estructura patriarcal dominante tiene su origen en una evolución socioeconómica que preexistía al Islam y que, posteriormente, fue legitimada por una interpretación conservadora de la religión que 
acabaría cristalizando en los siglos posteriores y que acabaría siendo aceptada de forma mayoritaria como la interpretación ortodoxa"1.

En la actualidad continúa siendo una sociedad profundamente estratificada desde el punto de vista sexual. Esta estructura social configura la vida de las mujeres de forma decisiva. Las consecuencias del patriarcado se dejan sentir en múltiples aspectos que tienen una influencia directa sobre las condiciones de vida de las mujeres y sus posibilidades de desarrollo personal y social.

La división sexual del trabajo es muy marcada, la inmensa mayoría de las mujeres son responsables de las tareas de la crianza de los hijos y del cuidado de la casa en exclusiva, mientras que los varones se ocupan de las actividades económicas, políticas, religiosas, educativas, jurídicas, etc. La actividad de las mujeres en estos espacios "públicos" es minoritaria, para poder acceder a ellos se precisa haber recibido un nivel de educación básica, al menos, y algún tipo de formación profesional.

A nivel estatal, la educación de las niñas, entendida como una herramienta imprescindible para desempañar un trabajo socialmente valorado y retribuido, se aprecia en un grado muy inferior a la de los niños. Existe en Pakistán, como en tantos otros países, un sistema educativo que tanto por su duración como por su contenido curricular discrimina a las niñas y a las jóvenes.

De acuerdo con los datos presentados por el Gobierno de esta nación a la CEDAW en $2007^{2}$, el índice de alfabetización de la población total del país en personas mayores de 15 años en 2004 era del 51'6\%, repartido entre un $63^{\prime} 7 \%$ de alfabetizados varones y un $39^{\prime} 2 \%$ de mujeres. Por lo que respecta a la población rural solamente el $41^{\prime} 6 \%$ saben leer y escribir, de los cuales el $56^{\prime} 3 \%$ son varones y el $26^{\prime} 6 \%$ mujeres. En las áreas rurales un alto porcentaje de niñas no está escolarizado y las que acuden a la escuela abandonan sus estudios precozmente. Parece ser que el Estado no pone los medios necesarios como para asegurar la asistencia a la escuela de las niñas en los mismos términos que los niños.

La educación primaria, por su parte, cuenta con un número de centros masculinos mucho mayor que femeninos, ya en este nivel básico de enseñanza en el que se realiza el proceso de alfabetización: el 55'1\% son centros para niños, el $32^{\prime} 3 \%$ para niñas y el $12^{\prime} 6 \%$ son centros mixtos. Este porcentaje de centros disminuye en un $90 \%$ en el nivel de secundaria, lo que da cuenta del elevado número de niños y niñas que abandonan la escuela a los 10 años cuando finalizan la enseñanza primaria, y del pequeño número de estudiantes del nivel secundario en el país.

1. Giunchi, E., "La situación de la mujer en Pakistán" en Derechos y Libertades: Revista del Instituto Bartolomé de las Casas 6 (2001), pp.105-116.

2. CEDAW (ONU) (2007) Responses to the list of issues and questions for consideration of the combined initial, second and third periodic report of Pakistan. Obtenido de: <http://daccessdds-ny.un.org/doc/UNDOC/GEN/N07/254/04/PDF/N0725404.pdf?OpenElement> [6-1-2011]. 
Por otra parte, en los curricula de las asignaturas y en los libros de texto se promueven los estereotipos de género y existe una importante oposición por parte de determinados grupos sociales a que se incluyan temas sobre los derechos humanos en los programas docentes.

Es decir, la estructuración sexual tiende a perpetuarse en la sociedad mediante la transmisión de sus valores a través de la educación formal e informal del país. Las consecuencias para las niñas, jóvenes y mujeres se concretan en que se les sustrae la posibilidad de desarrollar las capacidades intelectuales, morales, personales y sociales que proporciona la educación formal, y el desarrollo de habilidades técnicas o profesionales que constituyen un aporte importante del desarrollo de cada ser humano; además, contribuyen a que asuman como algo natural su condición de personas subordinadas a personas; y en tercer lugar, la sociedad no les proporciona herramientas para poder desempeñar un empleo o un trabajo que les permita disfrutar de autonomía económica y reconocimiento social, por ello se encuentran sin recursos y destinadas a depender de un varón si quieren sobrevivir con una cierta dignidad social.

El sistema de dominio del varón sobre la mujer genera y mantiene las condiciones sociales e institucionales que aseguran su vigencia. El escaso desarrollo educativo de las mujeres produce en ellas una inseguridad intelectual y moral que las hace psicológicamente dependientes del varón, este hecho se refuerza mediante la transmisión del sentimiento de inferioridad ante el fenómeno del menor número de centros escolares para niñas, que les hace sentir el poco aprecio social que merece su educación en relación con la de los varones y, por otro lado, asumen que la subordinación de las mujeres es algo natural a través de los valores que se aprenden explícita o implícitamente en los curricula de las asignaturas y de la educación informal. Todo lo anterior garantiza la aceptación de la subordinación personal, pero, además, esta situación psicológica viene acompañada y fortalecida por condiciones materiales, porque sustrayendo a las mujeres el derecho a la educación que les dotaría de capacidades para poder desempeñar trabajos remunerados, se les sustrae también la posibilidad de tener ingresos económicos que les permitan mantenerse y se ven en la situación de necesitar depender de un varón. Los mecanismos patriarcales son muy poderosos y se refuerzan unos a otros.

Como consecuencia la mayor parte de las mujeres se encuentran subordinadas y tutorizadas por varones y carecen de hecho (aunque no legalmente) de autonomía personal y económica. Los varones: esposos, padres o hermanos, ostentan la jefatura de la familia.

El hecho de la imposibilidad, para la mayoría de las mujeres, de encontrar un puesto de trabajo queda reflejado en estos datos obtenidos de la base de datos del World Bank ${ }^{3}$ :

3. World Bank (2007): World Development Indicators. Washington D.C. Obtenido de:<http://data.worldbank.org/indicator/SL.TLF.CACT.MA.ZS/countries> [2-4-2011]. 
El porcentaje de mujeres mayores de 15 años que desempeñan en Pakistán un trabajo remunerado es del $21 \%$, de éste, el $72 \%$ está constituido por mujeres que se ocupan en tareas agrícolas, el 15\% trabaja en el sector servicios y el $12{ }^{\prime} 5 \%$ en el sector industrial.

El número de varones mayores de 15 años que desempeñan un trabajo remunerado es del $84 \%$. Las cifras hablan por si solas y su mensaje es que muy pocas mujeres poseen autonomía económica con la que valerse por sí mismas.

Podemos suponer que en estas condiciones muy pocas mujeres acceden a desempeñar puestos representativos de responsabilidad a nivel político.

Pakistán, como es sabido, formaba parte de India durante la colonización británica. Ya en 1935, mediante el acta de Gobierno, el Reino Unido otorgaba una mayor autonomía a India en sus territorios de India, Pakistán y Bangladesh, y reconocía el derecho de sufragio a las mujeres bajo ciertas condiciones, es decir que con anterioridad a la independencia, las mujeres de este país tenían ya reconocido su derecho a voto.

Después de su independencia de India y de su consolidación como nación aprobó una Constitución occidentalizada, muy influida por las ideas liberales inglesas. En ella se consideraba que las prácticas discriminatorias, también en cuanto al derecho a la participación política, son ilegales. En la actualidad continúa vigente el principio de no discriminación y el derecho a formar parte de la vida pública del país.

Pakistán es una República semipresidencialista, su estructura estatal posee los mecanismos necesarios para el ejercicio de un modelo democrático de gobierno.

El artículo 25 de su Constitución dice así:

"25. Igualdad de los ciudadanos:

(1) Todos los ciudadanos son iguales ante la ley y tienen derecho a igual protección de la ley.

(2) No habrá discriminación basada en el sexo.

(3) Nada en este artículo impedirá al Estado tomar cualquier medida especial para la protección de las mujeres y los niños.

Y en su artículo 17:

17. Libertad de asociación:

(1) Todos los ciudadanos tendrán el derecho de formar asociaciones o agrupaciones, sujetas a cualquier restricción razonable impuesta por la ley en el interés de la seguridad e integridad de Pakistán, del orden público o la moralidad.

(2) Todos los ciudadanos... tendrán el derecho a formar o ser miembros de un partido político...

(3) Todos los partidos políticos contarán para sus recursos con sus propios fondos de acuerdo con la ley". ${ }^{4}$

4. The Constitution of the Islamic Republic of Pakistan. Obtenido de: <http://www.pakistani.org/pakistan/constitution> [19-4-2011]. (Traducción: la autora). 
Como se puede apreciar la ley prohíbe la discriminación en razón de sexo y reconoce el derecho de toda la ciudadanía a formar o ser miembros de partidos políticos.

Además Pakistán firmó y ratificó en 1996 la Convención sobre la Eliminación de todas las formas de Discriminación hacia las Mujeres (CEDAW), un organismo de las Naciones Unidas, con programas de acción para garantizar la no discriminación de las mujeres por parte de los Estados firmantes, en todos los ámbitos de los derechos humanos.

En relación con los derechos civiles, en concreto con el derecho de participación política, la Convención tiene redactados y aprobados los artículos siguientes:

"Artículo 7

Los Estados Partes tomarán todas las medidas apropiadas para eliminar la discriminación contra la mujer en la vida política y pública del país y, en particular, garantizando, en igualdad de condiciones con los hombres el derecho a:

a) Votar en todas las elecciones y referéndums públicos y ser elegibles para todos los organismos cuyos miembros sean objeto de elecciones públicas;

b) Participar en la formulación de las políticas gubernamentales y en la ejecución de éstas, y ocupar cargos públicos y ejercer todas las funciones públicas en todos los planos gubernamentales;

c) Participar en organizaciones y asociaciones no gubernamentales que se ocupen de la vida pública y política del país.

Artículo 8

Los Estados Partes tomarán todas las medidas apropiadas para garantizar a la mujer, en igualdad de condiciones con el hombre y sin discriminación alguna, la oportunidad de representar a su gobierno en el plano internacional y de participar en la labor de las organizaciones internacionales". ${ }^{5}$

El Gobierno de Pakistán, en su programa de acción positiva para la promoción de las mujeres, estableció una cuota de escaños reservada para ellas en todos los organismos federales, provinciales y locales, constituidos por miembros elegidos en los correspondientes procesos electorales. Concretamente el 17\% de escaños en la Asamblea Nacional, las Asambleas Provinciales y el Senado, y un $33 \%$ en las concejalías locales. Así mismo también se decidió reservar el 5\% de puestos de la administración pública para ellas.

Sin embargo, aunque la ley establece una igualdad de derechos legales e, incluso, apruebe medidas de discriminación positiva, no significa que las oportunidades para ejercerlos sean las mismas para ambos sexos. Aunque no

5. CEDAW (ONU) (1979) Full Text of the Convention: art. 7 y 8. Obtenido de: <http:// un.org/womenwatch/daw/cedaw/text/econvention.htm> [21-4-2011] (Traducción: la autora). 
existen restricciones en la ley, estas restricciones están y se derivan del sistema de estratificación de sexos vigente en Pakistán.

En el art. 4 punto 8 . del $38^{\circ}$ periodo de sesiones del Comité para la Eliminación de la Discriminación contra la Mujer (2007) de las Naciones Unidas, en la Lista de Cuestiones y Preguntas relativas al examen de un informe inicial y un informe periódico del Estado de Pakistán, se manifiesta:

"En el informe se indica que, aunque el Gobierno ha establecido un cupo del 5\% para las mujeres en la administración pública, del 17\% en la Asamblea Nacional, el Senado y las asambleas provinciales, y del 33\% en la mayoría de los niveles de los órganos municipales, "las providencias adoptadas al respecto no han generado los progresos que se había previsto" y "el Ministerio para el Adelanto de la Mujer se esfuerza por conseguir una mayor coherencia de los programas estatales de medidas positivas impulsando el Plan de Acción para promover reformas a favor de la igualdad entre los géneros" (págs. 25 y 26). Sírvanse facilitar detalles acerca de las reformas contempladas en el marco de ese Plan de Acción y el plazo previsto para su ejecución". ${ }^{6}$

Las medidas de discriminación positiva adoptadas por el gobierno, no impiden que exista una gran diferencia entre hombres y mujeres en relación con la participación política.

Según datos del Examen del Informe presentado por Pakistán, realizado por el Comité, como resultado de las elecciones generales de octubre de 2002, los escaños reservados en el Senado y en la Asamblea Nacional fueron sobrepasados, no así en las Asambleas Provinciales y en las concejalías locales en los que las reservas no se cubren, a pesar de que no son paritarias.

Los obstáculos fundamentales de esta situación son:

- El analfabetismo, que impide que los ciudadanos tengan acceso a la información necesaria para participar plenamente en el proceso democrático. Ya vimos anteriormente que la mayor parte de la población analfabeta está constituida por mujeres, sobre todo de las zonas rurales.

- La pobreza, que requiere de todos los esfuerzos para la supervivencia y disminuye la posibilidad de ejercer los derechos.

- La formación deficiente. Las mujeres tienen menos estudios y formación que los hombres, como hemos indicado más arriba, lo que significa que se encuentran menos preparadas para desempañar cargos públicos y de representación política, así como para entrar a formar parte de los organismos en los que se toman decisiones que afectan a la comunidad.

- Los estereotipos de género presentes en las familias conservadoras que actúan fuertemente sobre las motivaciones de las mujeres para que se

6. CEDAW (ONU) (2007) Lista de cuestiones y preguntas relativas al examen de un informe inicial y un informe periódico de Pakistán. Obtenido de: <http://daccess-dds-ny.un.org/doc/ UNDOC/GEN/N06/555/26/PDF/N0655526.pdf?OpenElement>[3-4-2011]. 
dediquen a desarrollar su vida en el espacio privado, considerando que el ámbito público está reservado para los varones.

- Los roles sociales asignados a las mujeres, tradicionalmente dedicadas al cuidado de su familia y sin medios económicos propios, lo que les impiden disponer de tiempo y de los recursos financieros necesarios para presentarse a unas elecciones.

- Carencia de documentos de identidad. Hay muchas más mujeres que hombres que carecen de partida de nacimiento por no haber inscrito éste en la Administración. Tratar de subsanar esta situación es un tarea complicada que requiere tiempo e información, por lo que la mayor parte de las personas no llegan a inscribirse, sobre todo mujeres que tienen más dificultades para informarse y menos disponibilidad temporal. Pero si se carece de partida de nacimiento no se puede obtener el documento de identidad, y sin éste no se puede votar. Es decir que hay miles de habitantes de Pakistán (millones, según Aurat Foundation ${ }^{7}$ ) en edad de votar, en su mayoría mujeres, que no se encuentran en los censos electorales y que por lo tanto no pueden ejercer su derecho a voto.

- Los impedimentos para la libertad de circulación de las mujeres. Éste es un problema sustancial en ciertas zonas del país. Se conocen informes de todas las provincias según los cuales se impide que las mujeres ejerzan su derecho a voto y presenten sus candidaturas. En numerosos ayuntamientos los escaños reservados a las mujeres quedan vacíos. Muchos de los concejales elegidos y algunas organizaciones de la sociedad civil han denunciado repetidamente esta situación ante la opinión pública.

Existen leyes que sancionan a quienes impiden a otros ejercer sus derechos a la participación política, concretamente el Acta de Representación Popular de 1976 y las Normas de Representación Popular (Celebración de Elecciones) de $1977^{8}$.

En ciertas zonas del país se impidió ejercer el derecho a voto a las mujeres en las elecciones municipales y en las generales de octubre de 2002. Con motivo de ello se entabló una querella ante el Tribunal Supremo de Penshawar, el cual determinó dos años después, en 2004, que no se podía impedir que las mujeres ejercieran sus derechos políticos. Sin embargo el Tribunal no declaró nulas las elecciones en las que el electorado femenino no pudo emitir su voto.

En las elecciones de 2005 no se permitió a las mujeres emitir su voto ni presentarse a las elecciones en algunos distritos de la provincia de la Frontera del Noroeste, a causa de ello la Comisión Electoral de Pakistán declaró nulas y sin valor las elecciones de siete colegios electorales y de algunos ayuntamien-

7. Aurat Foundation, Islamabad 05, 2008. Obtenido de <http://www.af.org.pk $>$ [22-4-2011].

8. Para conocer el sistema electoral pakistaní se puede consultar en: <http://www.observatorioelectoral.es/ImgBase/Caracter_sticas_del_sistema_electoral_pakistan_.pdf>. 
tos y se concedió a las candidatas de los distritos en los que se había ejercido violencia contra ellas, un tiempo adicional para presentar sus candidaturas, al tiempo que se emprendieron acciones judiciales contra los responsables de estas irregularidades.

Como vemos, las leyes y normas que sancionan la violación de los derechos de participación política se ejercen y aplican, y se puede decir que cubren casi todas las situaciones en que las mujeres pueden ser impedidas a ejercer sus derechos como electoras y como elegibles.

No obstante, a pesar de estos ejemplos de sentencia y aplicación de las normas, existen importantes dificultades para la aplicación de estas leyes, y ello las hace débiles. Una de ellas puede ser atribuida a la ausencia de preparación y falta de recursos de las autoridades que hacen cumplir la ley, otra se debe a los fallos de las personas, incluyendo las propias mujeres, cuyos derechos electorales han sido violados, para presentar una reclamación, y también la ausencia de testigos para sustanciar la reclamación. Las leyes serían más fáciles de aplicar si la oposición fuera violenta o por la fuerza, pero en el caso de las mujeres, en las que todo transcurre en la privacidad de sus hogares, nunca es notorio que se emplee la fuerza y, por otro lado, nunca o en muy pocos casos estas mujeres presentan la denuncia correspondiente.

Aunque exista una igualdad legal entre hombres y mujeres, es evidente que unos y otras no disponen de las mismas oportunidades. El analfabetismo, la pobreza, la falta de formación, los estereotipos culturales, los roles sociales, la falta de documentación y la opresión doméstica, afectan sobre todo a las mujeres, y su baja participación política es una consecuencia de estas discriminaciones. No hay restricciones legales, pero las hay reales, y fuertemente implantadas, a causa de este situación de privilegio masculino que genera sistemáticamente todos y cada uno de los obstáculos enumerados para impedir la pérdida de su estado de hegemonía privilegiada.

En este sistema patriarcal el poder se encuentra concentrado en manos de un élite definida primariamente en función de criterios sexuales, aunque también, secundariamente, económicos, políticos, raciales, etc.

El pleno ejercicio de los derechos políticos de las mujeres cuestiona una de las prerrogativas esenciales de los hombres: el monopolio en la gestión de la cosa pública. Si no existiera discriminación y la participación y representación política fuera indistintamente ejercida por hombres y mujeres, se tambalearía la propia estructura de poder, se ampliaría el contenido del debate político, y se modificaría la naturaleza de muchas de las decisiones.

Reconocer a las mujeres como sujetos reales de plenos derechos de ciudadanía significa una pérdida del poder absoluto e indiscutible del varón.

Para ello se decide que la "naturaleza" de las mujeres y su papel en la sociedad no las hace aptas para asumir el poder político, que su puesto está en el ámbito privado y su función es la reproducción. 
Las consecuencias de esta situación son trascendentes para las mujeres, suponen la continuación de su subordinación al poder patriarcal, a la discriminación y desigualdad, sus reivindicaciones quedan en manos de "la buena voluntad" de los hombres.

La ausencia de mujeres en la esfera pública las deja indefensas en cuanto al establecimiento de los principios y decisiones que afectan a las leyes y normas que regulan su conducta, constituyendo un colectivo que opone apenas resistencia y muy fácilmente manejable por las instituciones.

Las posibilidades que proporciona el desempeño de cargos públicos son importantes, se tiene la oportunidad de disponer de la capacidad para hacer propuestas legislativas, para tomar decisiones sobre la programación y realización proyectos sociales que ayuden en la promoción educativa y laboral de las mujeres, para elaborar estrategias educativas que promuevan la modificación de los estereotipos culturales discriminatorios mediante la acción de los medios de comunicación, etc.

Pero con motivo de estas transformaciones, los varones verían mermar su poder y su posición hegemónica indiscutible.

Como es sabido, los sistemas democráticos implican, por definición, el derecho de los ciudadanos a la libertad de expresión. Según Sheyla Benhabib (2008) ésta es la capacidad que poseemos todos los seres humanos, en tanto hablantes, para aceptar o rechazar la validez de unas normas que comprendemos y de acuerdo a las cuales podemos actuar. El derecho al ejercicio de la libertad comunicativa presupone el que todos somos igualmente merecedores de escuchar y de que se nos escuche, todos somos iguales para participar en la comunicación, todos tenemos derecho a iniciarla, a preguntar, a responder, a aportar elementos nuevos, a iniciar una reflexión sobre las propias normas comunicativas.

"Para ejercer la libertad comunicativa es preciso que se respete tu capacidad para una agencia incardinada, tu capacidad para la comunicación así como para la acción. Es necesario que se te reconozca como un miembro de una comunidad humana organizada en la que tus palabras y tus actos te sitúen dentro de un espacio social de interacción y comunicación" ${ }^{9}$

Un país que respete la libertad comunicativa a una parte de su población y se la niegue a la otra, de forma legal o real, en razón de su género, es porque no reconoce su común humanidad.

Como se puede deducir por estos datos, la implicación masculina en las esferas económica y política es abrumadora, ello les permite acceder a los recursos y bienes sociales y les sitúa en una posición de gran ventaja respecto

9. Benhabib, S., "Otro universalismo: sobre la unidad y diversidad de los derechos humanos". Isegoría: Revista de Filosofía Moral y Política 39 (2008), pp. 175-203 (p. 190). 
de las mujeres, que se ven privadas de la posibilidad de desenvolverse en esos espacios y de conseguir las recompensas sociales correspondientes, recompensas sociales que podemos traducir en ingresos económicos, desempeño de roles que proporcionan prestigio social, oportunidades para la promoción profesional, para el desarrollo personal, etc.

El acceso de los varones a estos bienes les dota de poder sobre las mujeres, poder en sentido weberiano, es decir, capacidad para decidir sobre su conducta a cambio de proporcionarle los recursos que necesita para desarrollar su vida y de los que ella se ve privada por su falta de educación y la ausencia de oportunidades de trabajo.

La división sexual del trabajo sitúa a los hombres en la esfera pública económica y política, son ellos los que monopolizan los roles de la élite social. En estos roles se acumulan el poder y la autoridad, las personas que los desempeñan controlan los recursos de sus organizaciones y utilizan su poder, entre otras cosas, para proporcionar oportunidades y recompensas a sus afines, entre los que se encuentran los que pertenecen a su mismo sexo.

Las élites, además, tienen el poder de crear, difundir y mantener la ideología sexual y las normas sexuales, que refuerzan y legitiman el sistema de estratificación sexual. Como las élites en Pakistán son abrumadoramente masculinas, la ideología sexual y las normas sexuales son profundamente androcéntricas.

En este país, la ideología sexual se encuentra atravesada de creencias sobre la superioridad masculina y su derecho a someter a las mujeres, que son por naturaleza inferiores. Estas ideas se legitiman sobre todo en la tradición tribal preislámica, pero también en la religión islámica y sus ideas acerca de cuál debe ser el papel de las mujeres en sus códigos morales. Las creencias y valores culturales tienen una fuerte influencia en el modo de entender y vivir la relación entre los sexos y ambos legitiman de forma importante la desventaja femenina. La comunidad femenina hace frente a una discriminación procedente de costumbres y tradiciones centenarias. Constituyen el 49\% de la población, que es marginada por las estructuras políticas, sociales y económicas del país.

Por lo que se refiere a las normas sexuales, que son las expectativas sociales de la conducta de las personas sobre la base del papel que se les asigna en función del sexo, en Pakistán hay un acuerdo social ancestral y la violación de estas expectativas Ileva aparejadas fuertes sanciones.

Las Leyes de Familia Pakistaní son un exponente de la vigencia de normas sexuales discriminatorias.

Hasta ahora hemos constatado que aunque las leyes son igualitarias en los aspectos que hemos examinado, sin embargo la discriminación se encuentra fuertemente presente en la realidad. Ahora veremos que existe también desigualdad por razón del sexo sancionada por las leyes, en las normas que regulan la conducta en los espacios más directamente relacionados con los papeles sociales que la cultura asigna a las mujeres, son las Leyes de matrimonio y familia 
que se encuentran recogidas en la Ordenanza de 1961 denominada Muslim Family Laws Ordinance (MFLO) ${ }^{10}$, en ellas se regula lo perteneciente al Ilamado estatuto personal: herencia (art. 4), registro de matrimonio (art. 5), poligamia (art. 6), repudio (art. 7), divorcio (art. 8), mantenimiento económico (art. 9).

Nos interesa, sobre todo, examinar las normas referentes a la poligamia, al repudio y al divorcio.

En el art. 2 de la Constitución de Pakistán se declara que el Islam es la religión oficial del Estado, lo que quiere decir que ninguna ley debe ser incompatible con las prescripciones del Corán y la Sunnah.

La poligamia está permitida en el Islam. De acuerdo con el contenido de la doctrina de esta religión referente al matrimonio, un hombre puede tener hasta cuatro esposas.

Las leyes pakistaníes recogen en sus ordenanzas la regulación de este estado civil.

Sin embargo, la necesidad de compatibilizar el espíritu occidental que inspira la Constitución, con los compromisos adquiridos con la poderosa institución religiosa islámica, empujó a los legisladores en 1961 a suavizar las condiciones de la poligamia tal como se encontraba en los textos legales anteriores, de forma que se tuviera más en cuenta los derechos de las mujeres. Hasta entonces un hombre podía casarse varias veces manteniendo sus esposas, sin ningún tipo de requisito especial que limitara este derecho.

Según informe de la firma de abogados Zafar\&Associates-LLP en Pakistán $(2011)^{11}$, la MFLO instituyó algunas modificaciones que limitaron la ley relativa a la poligamia, con la introducción de la exigencia de que el marido debe presentar una solicitud y pagar una tasa a la oficina local del Consejo de la Unión, con el fin de obtener el permiso previo y por escrito para la contratación de un matrimonio polígamo. La solicitud deberá explicar los motivos de la propuesta de matrimonio e indicar si el solicitante ha obtenido el consentimiento de la esposa o esposas existentes. El presidente del Consejo de la Unión forma un Consejo de Arbitraje con los representantes de la esposa o esposas existentes y el demandante a fin de determinar la necesidad de la propuesta de matrimonio.

La pena de contraer un matrimonio polígamo sin el permiso previo es que el esposo deberá pagar inmediatamente la dote entera a la esposa o esposas ya existentes, además de ser sujeto a una multa y/o encarcelamiento.

Cualquier matrimonio polígamo contraído sin la aprobación del Consejo de la Unión no puede ser registrado bajo el MFLO. Sin embargo, si un hombre no tiene el permiso de su esposa o esposas existentes o del Consejo de la Unión, su posterior matrimonio sigue siendo válido.

10. Ordenanza de las Leyes de familia Musulmana de 1961. Obtenido de: <http://www. vakilno1.com/saarclaw/pakistan/muslim_family_laws_ordinance.htm> [7-5-2011].

11. Zafar\&Associates-LLP (2011). Obtenido en: <http://www.zallp.com/family.html> [7-5$2011]$. 
Por otra parte, según lo que indica la jurisprudencia, el Poder Judicial suele resistirse a aplicar las sanciones contenidas en el MFLO y esto restringe la eficacia de las disposiciones de la reforma. Este hecho ha llevado a algunos observadores a describir las disposiciones que requieren la autorización del Consejo de Arbitraje como una simple formalidad.

No obstante, las condiciones impuestas a la poligamia mediante el requisito de solicitud de autorización al Consejo de la Unión y la notificación de permiso de la esposa o esposas existentes, en caso de no ser satisfechas constituyen motivo legal suficiente para que la esposa o esposas anteriores obtengan un decreto de disolución del matrimonio.

Evidentemente la posibilidad de tener varias esposas permitida a los varones y regulada de la forma expuesta, no tiene reciprocidad para el caso de las mujeres, a las cuales les está prohibido tener más de un esposo, por esta razón la Ordenanza obliga a la novia a demostrar que no está casada para registrar su matrimonio, no así al novio es decir, que no necesitan informar acerca de su estado civil para contraer matrimonio.

Por lo que respecta al repudio constituye un procedimiento legal para obtener la separación matrimonial. Los hombres tienen el derecho de decidir unilateralmente la disolución de su matrimonio con sólo notificarlo al Consejo de la Unión.

La Ordenanza de las Leyes de Familia regula los procedimientos de notificación, así como las consiguientes a las situaciones que se plantean como consecuencia de la separación: la posibilidad de reconciliación, los procedimientos para la recuperación de la dote y las sanciones por incumplimiento.

La MFLO exige que el marido que se divorcia después de un talaq (pronunciación del repudio), debe comunicarlo por escrito al presidente del Consejo de la Unión. El presidente deberá trasladar una copia de notificación a la esposa. El incumplimiento de estos procedimientos se castiga con pena de prisión y / o una multa. Dentro de los treinta días siguientes a la recepción de la notificación de rechazo, el presidente debe constituir un Consejo de Arbitraje a fin de tomar medidas para lograr una reconciliación. En su defecto, un talaq que no se revoca, ya sea expresa o implícitamente, entra en vigor tras la expiración de noventa días a partir de la fecha en que fue entregado el aviso de repudio al presidente. Si la esposa está embarazada en el momento del pronunciamiento del talaq, el repudio no surtirá efecto hasta que hayan transcurrido noventa días o hasta el final del embarazo, si éste es posterior.

La falta de notificación invalidó los talaq hasta finales de 1970 y principios de 1980, a partir de entonces la práctica judicial ha reconocido como válidos los repudios aun cuando no hubieran realizado el procedimiento de notificación. A su vez, la introducción de la Ordenanza Zina en 1979 (que regula el delito de adulterio) hizo posibles actuaciones de abuso contra las esposas repudiadas, ya que quedan expuestas a acusaciones de adulterio después de su separación si sus maridos no notifican ésta al Consejo, tal como lo regula la MFLO, ya que sin esta notificación no se encuentran legalmente separadas. 
El divorcio es el modo como la mujer puede llegar a obtener la disolución de su matrimonio. Para ello debe interponer una demanda de divorcio ante el juez y debe ser capaz de demostrar que la relación con su pareja hace imposible vivir una vida "según los límites establecidos por Dios".

Los motivos por los cuales las mujeres pueden pedir el divorcio son entre otros: la ausencia de su marido durante cuatro años, la falta de mantenimiento durante dos años, la contratación por parte del marido de un matrimonio polígamo sin haberse atenido a los procedimientos legales establecidos, el encarcelamiento del marido durante siete años, la desatención por parte del marido para llevar a cabo sus obligaciones conyugales durante tres años, impotencia continua del marido desde el momento del matrimonio, la locura del marido durante dos años o una grave enfermedad, el ejercicio por parte de la esposa de su opción de la pubertad, es decir, si un tutor contrató su matrimonio antes de la edad de 16 y ella rechaza el matrimonio antes de la edad de 18 años (siempre y cuando el matrimonio no se haya consumado), la crueldad del marido (incluidos los malos tratos físicos o de otro tipo), el tratamiento desigual de las co-esposas, y cualquier otro motivo reconocido como válido para la disolución del matrimonio bajo la ley musulmana; el divorcio judicial también puede concederse sin consentimiento del marido si la esposa está dispuesta a renunciar a sus derechos económicos.

Mientras los esposos no necesitan ninguna justificación para repudiar a sus esposas, ni tienen que pasar por un proceso judicial, las mujeres tienen que justificar ante el juez las razones por las que desean divorciarse que, como vemos, están bastante reguladas e identificadas, y dependen de la sentencia de éste, por lo que de ningún modo su divorcio está garantizado.

No obstante, lo más terrible en el ámbito de las normas sexuales de este país es la concepción del honor. En todos los países patriarcales los hombres quieren asegurarse de la paternidad de sus hijos, sobre todo varones. Esta seguridad exige restricciones sobre la sexualidad femenina, de ahí que las normas sexuales para las mujeres, aunque no para los hombres, incluyen conductas directamente relacionadas con la castidad. En Pakistán el control de la vida sexual de las mujeres se ejerce con violencia. Los mecanismos más importantes de control de este aspecto de la vida de las mujeres, fuertemente implantados en Pakistán, tienen sus raíces en profundas creencias y costumbres ancestrales y proceden del significado del honor en la familia.

La honorabilidad es una cualidad imprescindible entre las familias pakistaníes para ser socialmente respetadas.

En las sociedades patriarcales musulmanas en general, y pakistaníes en particular, el honor no afecta únicamente a un individuo, dependiendo exclusivamente de sus acciones y modos de vida, sino que este carácter es comunitario, es todo el clan el que es honorable o, por el contrario, recae sobre él el deshonor cuando alguno de sus miembros no se comporta de acuerdo a determinadas pautas. 
Concretamente, las pautas de comportamiento que garantizan el honor del clan son las que regulan la conducta sexual de las mujeres. El honor de un hombre queda protegido mientras sus mujeres (esposas, hermanas, hijas) se comporten sexualmente de un modo adecuado y honesto.

Comportamientos honestos se consideran: la virginidad antes del matrimonio, la fidelidad una vez casadas.

Si estas normas de conducta sexual no se respetan, la familia entera queda deshonrada y sólo puede recuperar su honor si mata a la mujer que no ha respetado las normas (también puede marginarla, excluirla). Solteras embarazadas, aunque el embarazo haya sido a consecuencia de una violación, mujeres que no aceptan un matrimonio impuesto y huyen de casa, casadas de las que se tiene la mínima sospecha de un adulterio, deben morir, y son sus padres o hermanos quienes las matan.

Estas normas no proceden de la religión islámica, sino de costumbres tribales preislámicas. Tampoco tienen que ver con los códigos oficiales de justicia, sin embargo, aunque las leyes pakistaníes condenan estos crímenes, lo cierto es que los tribunales de justicia son muy benévolos con los asesinos porque se considera una circunstancia atenuante el móvil del honor, y los presos (si llegan a ser encarcelados), reciben un trato especial de favor.

Esta concepción del honor y las consecuencias que acarrea la transgresión de sus normas, solapadamente apoyadas por las instituciones, junto al sistema fuertemente patriarcal, determina el destino de las mujeres, que difícilmente pueden plantearse tener sus propios proyectos vitales.

\section{Conclusión}

En estas breves líneas hemos querido resaltar algunos de los aspectos culturales pakistaníes que más afectan a las mujeres y que nos permiten conocer, en parte, el modo en que este colectivo se encuentra inmerso en una situación de fuerte discriminación respecto al varón, exclusivamente en razón de su sexo. Hemos tratado de explicar los mecanismos de perpetuación de esta situación utilizados en esa sociedad, entre los que se encuentran la división sexual del trabajo y la imposición desde el poder de medidas sociales androcéntricas que condicionan fuertemente la educación de las niñas y jóvenes, las oportunidades de trabajo de las mujeres y su participación política, y las sitúa en una posición de inferioridad, vulnerabilidad y dependencia del varón. Esta posición de desventaja social se refuerza mediante la defensa y legitimación de la ideología de sexo y las normas sexuales tradicionales por parte de los varones desde sus posiciones de élite política y económica. La ideología de sexo y estas normas sexuales tienen una presencia decisiva en la vida de las mujeres obstruyendo sus posibilidades de desarrollo personal. La conclusión es que las mujeres en Pakistán constituyen un subgrupo oprimido y cosificado, cuya función es servir de soporte a los privilegios patriarcales. 


\section{Bibliografía}

AHRC (Asian Human Rights Comisión) AHRC-SPR-006-2009. Human Rights at Pakistan: 2009. Obtenido de: <http:/www.ahrchk.net/ua/mainfile.php/2009/3301/> [20-122010].

AMORÓS, C. (2005), "Feminismo y multiculturalismo", En Amorós, C. (ed) Teoría feminista: de la llustración a la globalización, vol. 3. Madrid: Minerva Ediciones.

AURAT FOUNDATION, Islamabad 05, 2008. Obtenido de: <http://www.af.org.pk/> [22-4-2011].

BALLESTER, L. y OLIVER, J.L. (2003), "Necessitats i conflicto. La mediació com a eina pedagógica en els processos d'inserció sociocultural dels inmigrants internacionals", Temps d'educación 27, 193-208.

BENHABIB, S. (2008), "Otro universalismo: sobre la unidad y diversidad de los derechos humanos". Isegoría. Revista de Filosofía Moral y Política 39, 175-203.

CEDAW (ONU) (2007), Responses to the list of issues and questions for consideration of the combined initial, second and third periodic report of Pakistan. Obtenido de: <http://daccess-dds-ny.un.org/doc/UNDOC/GEN/N07/254/04/PDF/N0725404. pdf?OpenElement> [6-1-2011].

CEDAW (ONU) (2007), Lista de cuestiones y preguntas relativas al examen de un informe inicial y un informe periódico de Pakistán. Obtenido de: <http://daccessdds-ny.un.org/doc/UNDOC/GEN/N06/555/26/PDF/N0655526.pdf?OpenElement> [3-4-2011].

CEDAW (ONU) (1979), Full Text of the Convention: art.7 y 8. Obtenido de: <http://www. un.org/womenwatch/daw/cedaw/text/econvention.htm> [21-4-2011].

The Constitution of the Islamic Republic of Pakistan. Obtenido de: <http://www.pakistani.org/pakistan/constitution/> [19-4-2011].

GIUNCHI, E. (2001), "La situación de la mujer en Pakistán", en Derechos y Libertades: Revista del Instituto Bartolomé de las Casas 6, 105-116.

MESTRE I MESTRE, R. (2000), "Puntos de partida para la crítica feminista al derecho de extranjería", en Asamblea de Mujeres de Córdoba Hierbabuena: Feminismo es... y será. Córdoba: Servicio de Publicaciones de la Universidad de Córdoba.

Ordenanza de las Leyes de Familia Musulmana de 1961. Obtenido de: <http://www. vakilno1.com/saarclaw/pakistan/muslim_family_laws_ordinance.htm> [7-5-2011].

SAMOUILLER, S. y JABRE, K. (2007), "La problemática del sufragio y de la participación política de las mujeres", en Ockrent, C., El Libro Negro de la Condición de la Mujer. Madrid: Santillana.

SALTZMAN, J. (1992), Equidad y Género. Madrid: Cátedra.

TAYLOR, Ch. (1993), El multiculturalismo y la "política del reconocimiento", traducción: Utrilla de Neira, M. México: Fondo de Cultura Económica.

WORLD BANK (2007), World Development Indicators. Washington D.C. Obtenido de: $<$ http://data.worldbank.org/indicator/SL.TLF.CACT.MA.ZS/countries> [2-4-2011].

Zafar\&Associates-LLP(2011). Obtenido de: <http://www.zallp.com/family.html> [7-52011]. 